\title{
The Effectiveness of a Nutrition Education Game "Food for Thought"' in Influencing the Food Selection Behavior of University Cafeteria Patrons
}

\author{
Syed A. Husain, Ph.D.
}

DOI: http://dx.doi.org/10.5915/17-1-12723

Because the eating habits of a nation affect its health, methods of influencing those eating habits are very important. Research was undertaken to measure the effects that an American Heart Association mutritional game would have upon the mean caloric intake, the percentage of meals with desserts, and the percentage of consumption of skim milk of patrons of a University Cafeteria. Patron food choices were unobtrusively measured for 16 weeks by means of a computerized cash register inventory system, then the effects of the media-based nutritional game were analyzed by intervention time series analysis. During promotion of the game, patrons of the cafeteria reduced their mean caloric intake by $5 \bullet$, percentage of desserts by $19 \bullet$, and increased consumption of skim milk by 40•. Of even more significance was the maintenance effects realized after the "Food for Thought" game ended. The changes in choices persisted after intervention (i.e. after the game). This paper documents the effectiveness of the "Food for Thought" game and also yields results generalizable to similar advertising campaigns and educational program.

\section{Introduction}

Nutrition is a foundation of good health. A knowledge of nutrition enables an individual to influence the quality of her/his health and well-being through individual responsibility and action. The application of nutrition knowledge can result in a change in food selection behavior for better health and well-being. Furthermore, most persons can add years to their lives by applying knowledge about nutrition to their selection and consumption of food.

In the past fifteen years, public interest in diet and health has increased dramatically. Part of this interest can be attributed to concern for the quality of food supply and recognition of the impact of nutrition on health. Part of this interest also can be attributed to advances in nutrition knowledge and food technology together with the publicity that has been given to this knowledge. In addition, it is now recognized that nutritional inadequacies can occur in a developed nation such as the United States.

There are various institutions in society which provide information to the public about food and its relation to health. Health departments and hospitals have classically been the source of much of the information people use to make decisions about their health behaviors. The public media have increasingly provided to the public information on health, through regular columns and feature articles in newspapers, special topic programs presented on television or radio, or through directly delivered community awareness program.

Nutrition education can be beneficial to all individuals regardless of income, cultural, social, economic, and educational background or geographic location. Obtaining the nutritional requirements of the body is not achieved in man by instinct nor is this knowledge inherited. Each generation learns what foods to select and why and how food affects health. Thus, individuals must be taught how to utilize the existing food supply in order to derive maximum nutritional benefit from it. According to Krause and Hunscher ${ }^{1}$, the function of nutrition education is to make it possible for persons to learn and to use nutrition information through individual responsibility and action.

If public health is to be served best by educating people regarding the role of nutrition and health, then, for maximum impact, such education should be conducted at the point where people choose what they will eat. Therefore, methods of influencing eating habits are important from an individual and societal perspective.

This research measured the effects that an American Heart Association ${ }^{2}$ mediabased nutritional game ("Food for Thought") has upon the mean caloric intake, the percentage of meals with desserts, and the percentage consumption of skim milk of patrons of a University Cafeteria. Food choices were unobtrusively measured for six weeks by means of a computerized cash register inventory system, then the "Food for Thought" game was introduced for a period of four weeks. During the game, patrons of the cafeteria reduced their mean caloric intake by $5 \%$, percentage of desserts by $19 \%$, and increased consumption of skim milk by $40 \%$. Of even more significance was that patrons maintained their new eating habits after intervention (i.e., after the game).

America's number one dietary problem is excessive caloric intake. According to Molitor ${ }^{3}$, overindulgence is directly responsible for overweight and obesity which

From Research and Development, Swift \& Co. Oakbrook, Illinois

Presented at the 17th Annual Convention of the

Islamic Medical Association in St. Louis, Missouri

August 10-12, 1984, Prize Award For Best

Paper presented

Address all correspondence to Dr. Syed A. Husain

Research and Development, Swift \& Company, 1919 Swift

Drive, Oakbrook, Illinois 60521 
plagues between 20 to $40 \%$ of the U.S. population. Other affluent countries suffer a similar fate. The solution that we all recognize is to reduce caloric intake and improve the nutritional quality of the calories consumed (e.g., less fats, empty calories, and cholesterol). While the application of this game has been reported, Zifferblatt et. al. ${ }^{4}$, past research did not model the effects of the game using intervention time series procedures. This research extends previous research through replications, and through the utilization of more powerful time series methods. The time series analysis of this study is to follow in a related article 5 .

One of the major motivating purposes of this research was to confirm the effectiveness of persuasive communications and cognitive dissonance in influencing behavioral choices of consumers through an educational game $^{6}$. The major substantive presentation of Hussain's research ${ }^{6}$ is to follow in a related article. Our purpose here is to present the results of the effectiveness of the "Food for Thought" game in influencing the food selection behavior of a target population.

The "Food for Thought" game was developed at the National Heart, Lung and Blood Institute as a mediabased, nutritional intervention program designed to influence food choices in cafeteria settings. The game imparts specific nutritional information about food normally served at lunch in cafeterias through the use of playing cards (Fig. 1). The deck consists of an enlarged (3" $x$ 5"), 52-card deck with jokers. Each card contains a different colorful and humorous nutritional message designed to educate the viewer in "proper" nutritional habits. Also, very importantly, the "Food for Thought" game presented nutritional messages in a very effective manner; authoritative, persuasive, and entertaining.

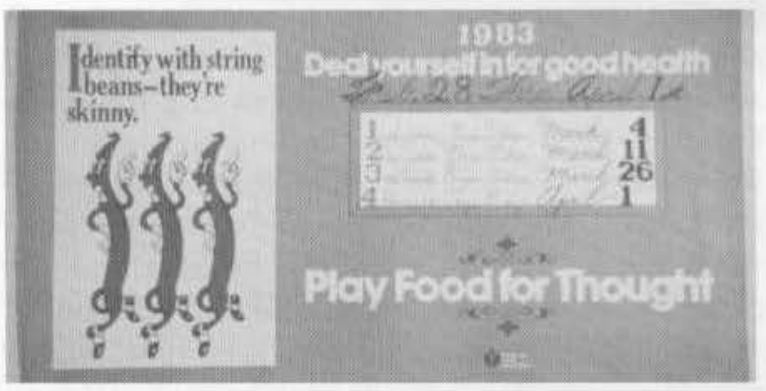

a

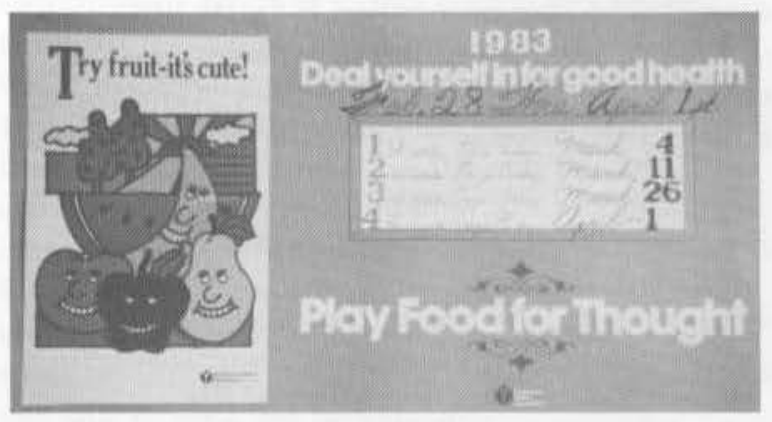

b

Fig. 1

\section{The Experimental Setting}

The University of Missouri-Kansas City (UMKC) cafeteria was the location for this study. The cafeteria serves a heterogenous population of students, faculty and administrative personnel. Approximately 1200 customers a day eat lunch at the cafeteria Monday through Friday. There are only 320 students who live in the University dormitory who have bought advance meal tickets and use the cafeteria regularly (UMKC has only about 500 resident students out of 11000 enrolled students).

\section{Data Collection}

A potential problem in collecting data over a period of several months is the stability of the population before, during, and after treatment. If an effect is to be measurable, then control of the population is essential. Table 1 presents the results of interviews of 500 patrons conducted over a five-day period. The stability of the population is apparent here with a typical number of lunches bought equalling 3.7 per week. These results yield the statistical conclusion that the actual average will not vary more than 0.58 from the calculated mean of 3.7 , 95 chances out of 100 .

The menu of the cafeteria features a variety of meals including 3 or 4 hot main dishes, salads, desserts, and a delicatessen bar. Entree menus are repeated every 21 days, not including Saturdays and Sundays.

The average daily caloric values of meals, the percentage of desserts and skim milk were measured unobtrusively for 30 days (i.e., 6 weeks) prior to February 25,1983 , to establish the preintervention processes. (More weeks would have been valuable in the study but, unfortunately, changes in students and menus on a semester schedule precluded this.) Patrons could select from approximately 90 food items each day. Caloric content of food items were calculated for all ingredients and then summed to obtain the total caloric value for the entire recipe ${ }^{7}$. The total caloric content of a recipe was divided by the number of servings to derive the caloric content of a sinle serving. The dependent variables are: (a) average caloric intake equals total calories purchased a day divided by the number of customers that day. (b) the percentage of desserts, and (c) the percentage of skim milk were calculated as the rate per 100 customers.

\begin{tabular}{|c|c|c|c|}
\hline Day & Mean* & Standard Deviation & Standard Errot \\
\hline Monday & 376 & 1.69 & $0.3 \mathrm{i}$ \\
\hline Tuesday & 3.36 & 1.69 & 0.31 \\
\hline Wednestay & 363 & 1.67 & 0.30 \\
\hline Thunday & 3.80 & 165 & 0.30 \\
\hline Friday & 3.40 & 1.47 & 0.27 \\
\hline AVERAGE & 373 & 1.63 & 0.298 \\
\hline
\end{tabular}




\section{The Game}

During the 4 weeks of intervention, February 28 through April 1, 1983, "Food for Thought" cards were distributed by cashiers every day (Monday-Friday). To encourage patrons to participate and save cards, incentives were offered. A player's objective was to collect specific combinations of cards to receive a prize of nominal value. In so doing, it was hoped that the consumer would read the messages on the cards.

During intervention, prizes were awarded at the end of each of the 4 weeks. The first week, patrons could win a National Dairy Council guide to good eating and food choices if they had "two pairs" or "three of a kind." At the end of the second week, a set of attractive kitchen posters was awarded for a "full house." A complete "Food for Thought" deck of cards (without jokers) or a cookbook was the prize at the end of three weeks for those with "four of a kind." Finally, at the end of the fourth week, a low calorie dinner for 2 was awarded to those with 4 jokers. In all, 428 decks of cards were given out and 10 point of purchase posters were displayed during the intervention (Figures 1 and 2). In addition, a research assistant was present at the cafeteria to answer any questions concerning the game during lunch hours.

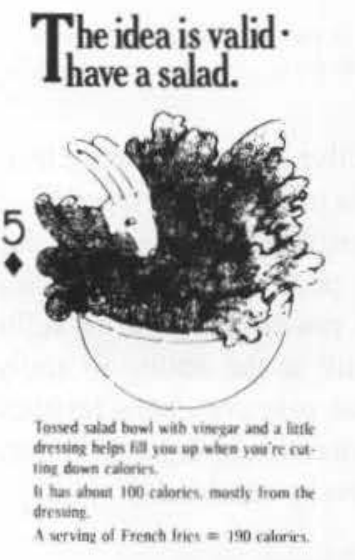

$\mathbf{a}$

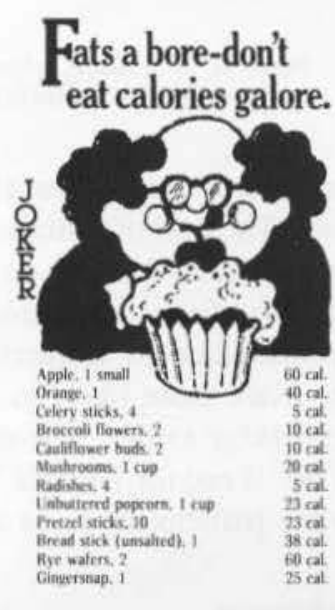

b
Fig. 2

Persons depleted by disease, traumatic stresses or prior dietary inadequacies were informed in the flyer distributed during the 2 weeks prior to intervention and also during the 4 weeks of intervention to seek their physicians' advice before heeding to the messages in the nutrition education game. It should be noted that prior to intervention, a written proposal was submitted to the chairperson of the Human Experimentation Committee of the University of Missouri, Kansas City, and was approved.

\section{Data Analysis}

During the six-week baseline period, the average daily caloric value of purchases per customer, and the food selection rate in the dessert category and sweet bread category and $2 \%$ milk and skim milk category were examined. At the end of the baseline period, the "Food for Thought" game was introduced for a period of 4 weeks. The effect of this program on average daily caloric purchases per customer and the daily food selected rate in the dessert and sweet bread category and $2 \%$ milk and skim milk category were examined by Box and Jenkins ${ }^{8}$ time series analysis. By plotting the average daily caloric purchases per customer as a function of time and the daily food selection rate in the dessert and sweet bread category and $2 \%$ milk and skim milk category, it was possible to test the effects of the "Food for Thought" game.

Figure 3 shows the average daily caloric value of purchases per day per customer at lunch in the UMKC cafeteria from January 17, 1983, through May 13, 1983, a total of 80 observations. Unobtrusive measurement of caloric value of purchases per day per customer at lunch were made from January 17, 1983, through February 25,1983 , a six-week period with 30 observations called as baseline data. On February 28, 1983, the 31st day of the series, the "Food for Thought" nutritional intervention program was introduced for a period of 4 weeks. A gradual, permanent change in the series (see Figure 3) was realized at the point of intervention suggesting that the strategy of the "Food for Thought" game was successful.

The intervention period of 20 observations (February 28, 1983, through April 1, 1983) and the post intervention period of 30 observations (April 4, 1983, through May 13, 1983) were found to be statistically equivalent. That is, no difference was found to exist in the processes behavior during or following the intervention. The series mean level was shown to be relatively constant from periods 36 to 80 . Alternate hypotheses concerning maintenance behavior and intervention effects were rejected. The maintenance effect persisted through period 80 at a level which is not statistically different than the intervention period (after it reached an equilibrium value). In fact, it appears that the average caloric intake continues to decline during the post intervention period. It was not within the scope of this study to determine whether this decline would have continued or was effected by other causes, such as final exams or seasonal

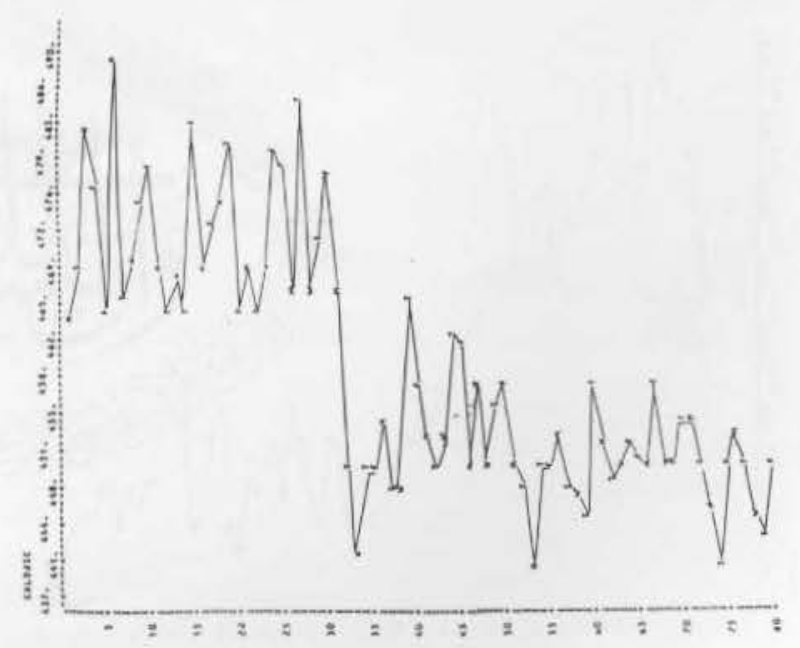

Figure 3. Average daily caloric value of purchases per customers in the UMKC cafeteria for 80 days. 
changes in eating habits. Even if such effects exist, they do not detract from the conclusions of this study. A study of such effects is a logical extension of this research.

During the preintervention period, the mean dessert rate was $26.56 \%$. On the first day of intervention, the percentage of desserts declined by $1.12 \%$; on the second day, $0.86 \%$; and on the third day, the decline was $0.67 \%$ for a total decline of $2.65 \%$ in three days ( $54 \%$ of the asymptotic value).

Also from the plot of the time series (Figure 4), we could see immediately that the impact is gradual and permanent effect, persisting until the end of the semester. It was significant that the effects persisted for 6 weeks after the completion of the game.

Prior to the intervention period, the mean skim milk rate was $2.89 \%$. Figure 5 shows the daily food selection rate in the $2 \%$ milk and skim milk category which denotes that the impat of the game was gradual and permanent. Actually, $44 \%$ increase in skim milk consumption was realized. While this effect is gradual, it is quite rapid, achieving $93 \%$ of the asymptotic effect in only 3 days.

\section{Discussion}

The purpose of this study was to test in the naturalistic setting, the use of a nutrition education game, "Food for Thought," to influence the food selection behavior of college cafeteria patrons. Persuasive communication in the form of a card game, "Food for Thought," which entertains and informs the participants was utilized along with pertinent supportive material from a high credibility source-- The American Heart Association. Overall, the messages emphasized a lower calorie food selection for lunch. The strategy presented in the "Food for Thought" game is similar to that used in food advertising and is derived from persuasive communication and cognitive dissonance theory. Analogous to a game where the player enter to "Win," the "Food for Thought" game offered incentives to the participants and, thereby, a game to "win" was created. Incentives were offered to create a cognitive dissonance among the participants. The result indicated that the main objective was achiev-

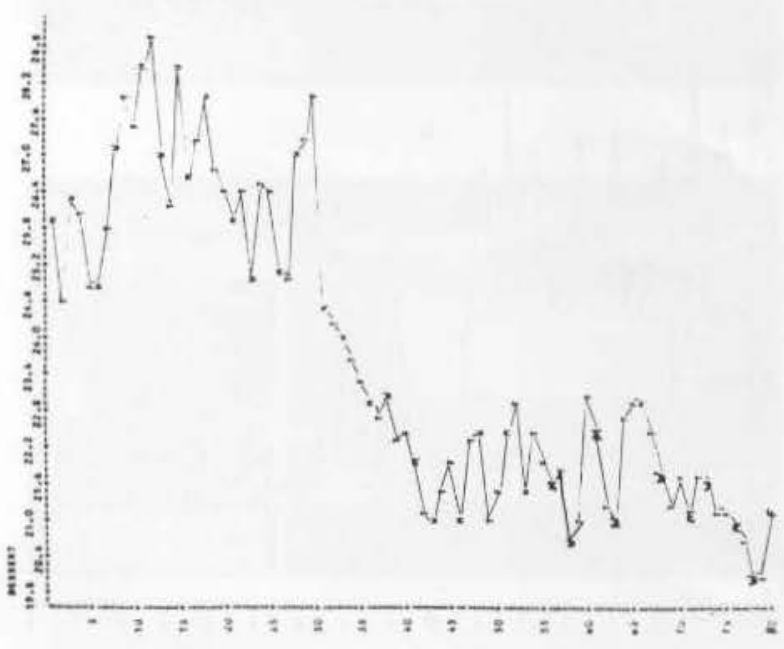

Figure 4. Daily rate of selection in the dessert and sweet bread categories in the UMKC cafeteria for 80 days. ed. On the average, UMKC cafeteria patrons purchased significantly fewer calories.

The results of this study have confirmed that entertainment is a powerful motivation and should not be overlooked as an important part of program design. Entertainment is, in fact, a powerful tool for motivating a learner. Closely related to the fun aspect of the game is the ability of the game to involve learners directly in the process of learning. Educators have known for

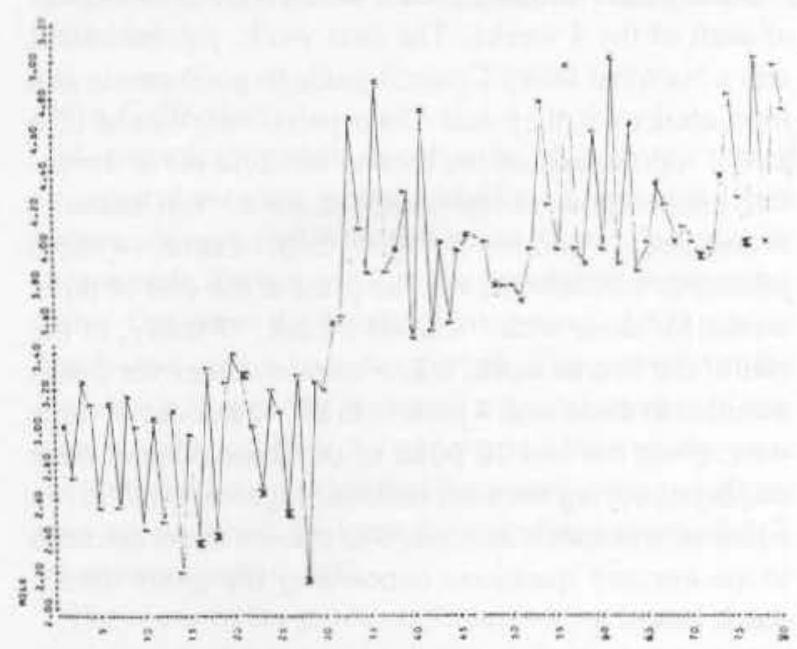

Figure 5. Daily rate of selection in the $2 \%$ milk and skim milk categories in UMKC cafeteria for 80 days.

many years that the most effective learning is active learning. The goal of education is to enable the learners to use their knowledge to do something. The result of this study confirms that learning processes which provide opportunities for learners to practice the use of skills are much more likely to result in the ability to apply knowledge to life. One of the primary characteristics of the "Food for Thought" game was giving opportunity to the participants to be actively involved.

\section{References}

1. Krause, MV and Hunscher, MA: Food Nutrition and Diet Therapy. Philadelphia: W.B. Saunders Co., 1972, p. 16.

2. American Heart Association, Food for Thought Game. Dallas: American Heart National Center, 1980.

3. Molitor, GTT: "The food system of the 1980s: communications perspectives for the 1980s." J. Nutr Edu, 12: 103-111, 1980.

4. Zifferblatt SM: et. al.; changing cafeteria eating habits. J. Am. Diet Assoc, 76: 15-20, 1980.

5. DeLurgio, SA and Hussain, SA: Measuring the influences of nutritional messages using ARIMA intervention methods. Accepted for the $1984 \mathrm{Na}$ tional meeting of the American Institute for Decision Science, Toronto, Canada.

6. Hussain, SA: The effects of persuasive communication an cognitive dissonance in influencing the food selection behavior of University cafeteria patrons. Unpublished dissertation. School of Education, University of Missouri Kansas City, Missouri, 1983. 
7. Adams, CF: Nutritive Values of American Foods in Common Units. U.S.D.A. Agricultural Handbook. 1980 , No. 456 .
8. Box, GEP and Jenkins, GM: Time-Series Analysis: forecasting and control. San Francisco. Holden-Day, 1976. 